\title{
Use of the infra hyoid musculo-cutaneous flap in soft palate reconstruction
}

\author{
P. Gangloff ${ }^{\text {a,* }}$, A. Deganello ${ }^{\text {b }}$, M.L. Lacave ${ }^{\text {a }}$, J.L. Verhaeghe ${ }^{c}$, \\ M. Lapeyre ${ }^{\mathrm{d}}$, F. Maire ${ }^{\mathrm{e}}$, B. Phulpin ${ }^{\mathrm{a}, \mathrm{e}}$, F. Guillemin ${ }^{\mathrm{c}}$, G. Dolivet ${ }^{\mathrm{a}}$ \\ ${ }^{a}$ Head and Neck Surgery Unit, Oncologic Surgery Department, Centre Alexis Vautrin, Avenue de Bourgogne, Brabois, \\ 54511 Vandoeuvre les Nancy Cedex, France \\ ${ }^{\mathrm{b}}$ Department of Otolaryngology/Head and Neck Surgery, National Cancer Institute Regina Elena, Rome, Italy \\ c Oncologic Surgery Department, Centre Alexis Vautrin, Avenue de Bourgogne, Brabois, 54511 Vandoeuvre les Nancy Cedex, France \\ ${ }^{\mathrm{d}}$ Radiotherapy Unit, Centre Alexis Vautrin, Avenue de Bourgogne, Brabois, 54511 Vandoeuvre les Nancy Cedex, France \\ e Dental Surgery Unit, Oncologic Surgery Department, Centre Alexis Vautrin, Avenue de Bourgogne, \\ Brabois, 54511 Vandoeuvre les Nancy Cedex, France
}

Accepted 17 July 2006

Available online 1 September 2006

\begin{abstract}
Aims: To review a series of 23 consecutive patients with squamous cell carcinomas arising from oropharynx who underwent infra hyoid musculo-cutaneous flap reconstruction including soft palate in alternative to free radial forearm flap or maxillofacial prosthesis. Post operative radiotherapy was performed for all patients.

Results: Every reconstruction healed quickly without major wound complications. The functional results evaluated by speech and swallowing capacities, were good for 17 patients, fair for 4 patients and bad for 2.

Conclusions: The infra hyoid musculo-cutaneous flap is a versatile, reliable and convenient flap suitable for repairing small and medium sized defects; it can be used in combination with other flaps, and in selected cases obviates the need for a microvascular free radial forearm flap or maxillofacial prosthesis.
\end{abstract}

(C) 2006 Elsevier Ltd. All rights reserved.

Keywords: Infra hyoid musculo-cutaneous flap; Head and neck; Cancer; Soft palate; Rehabilitation

\section{Introduction}

Velopharyngeal function is often compromised by the resection and reconstruction of oropharyngeal and palatal tumours. While free tissue transfer has improved the outcomes of head and neck reconstruction, in general, palatal reconstruction remains a challenge. ${ }^{1}$

The use of microvascular free flaps is the most widespread method currently employed for the reconstruction of extensive defects after resection of head and neck cancer, so that they represent today the golden standard in many cases because of their versatility and reliability. The flap most commonly used for head and neck reconstruction is the free radial forearm flap (FRFF). ${ }^{2}$ This FRFF can be used alone or

\footnotetext{
* Corresponding author. Tel.: +33 383598446 .

E-mail address: gangloffp@aol.com (P. Gangloff).
}

combinated with other local flaps. The study of Brown et al. ${ }^{3}$ shows that the addition of the superiorly based pharyngeal flap to the FRFF in soft palate reconstruction results in improved speech and swallowing. Brown et al. ${ }^{3}$ recommend the use of the additional flap in resections in which more than one quarter of the soft palate is included.

The evidence that not all the patients are suitable for a free flap reconstruction, and also that not every defect strictly requires a free flap transfer to achieve a good functional result, rises the necessity to find good alternatives.

Pectoralis major flap and temporalis flap are the most used pedicled flaps in head and neck reconstruction, but the infra hyoid musculo-cutaneous flap (IHMCF) is one of the alternatives to be considered for the reconstruction of moderate defects following resection of the oral cavity, oropharynx or hypopharynx cancers in selected cases. It obviates the need for a microvascular free flap or other local flaps in many cases. ${ }^{4}$ 
Here we report our experience of a series of 23 reconstructions for selected tumours of the soft palate by using the IHMCF, as a valid alternative to FRFF reconstruction or maxillofacial prosthesis.

\section{Patients and methods}

The infrahyoid muscles including sternohyoid ( $\mathrm{SH}$ ), thyrohyoid (TH), sternothyroid (ST) and omohyoid (OH) constitute the anatomical substratum of the flap, completed by the platysma and the overlying skin.

\section{Design of flap}

The IHMCF is designed as an oval vertically shape in a paramedian situation and can measure up to $10 \mathrm{~cm}$ in its greatest length and up to $5 \mathrm{~cm}$ widthways (Figs. 1 and 2). ${ }^{5-7}$ The extent of the resection goes from $1 / 4$ to $1 / 2$ of the soft palate. Patients for whom the resection reaches more than the half of soft palate were excluded from this series. The flap is dissected in order to separate it from the median cervical fascia. The inferior muscular part of the flap is defined by sectioning the muscles downwards (SH and ST) and outwards (intermediate tendon of $\mathrm{OH}$ ). The venous drainage has two systems through the anterior jugular vein and the superior thyroid vein. Then the strap

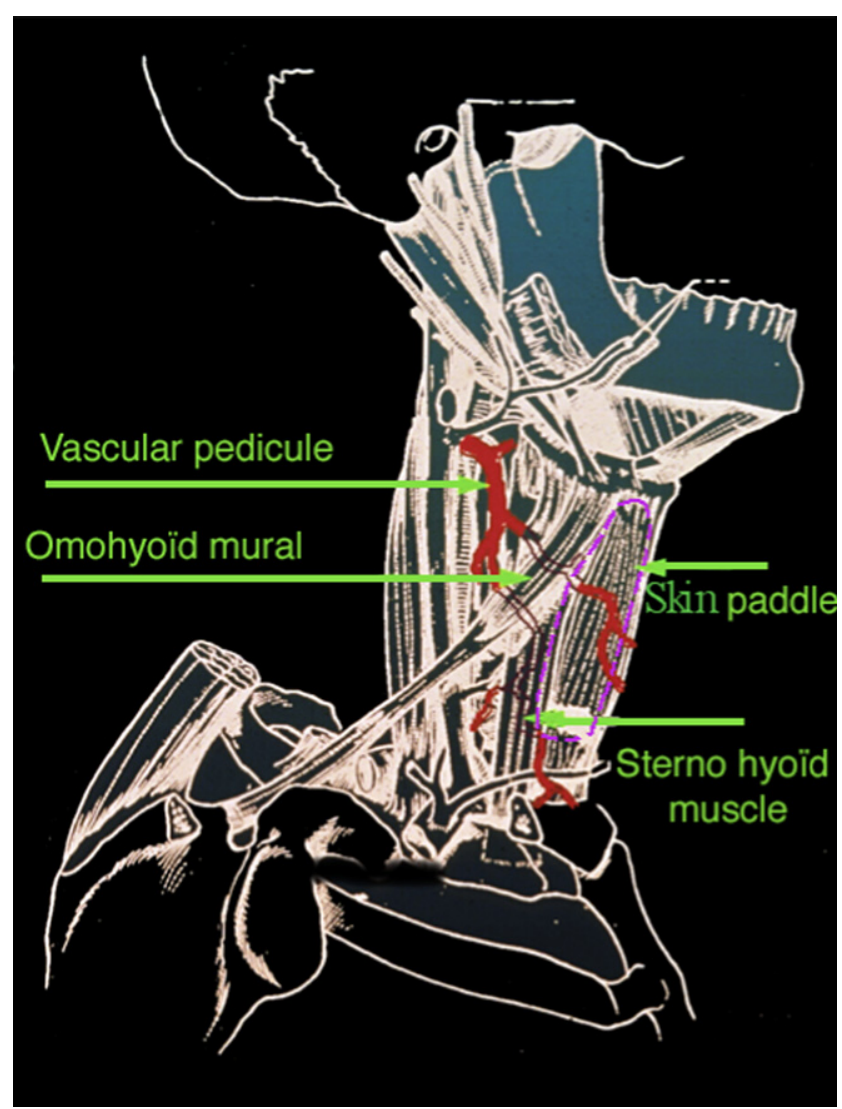

Figure 1. Infra hyoid musculo-cutaneous flap and its vascular network.

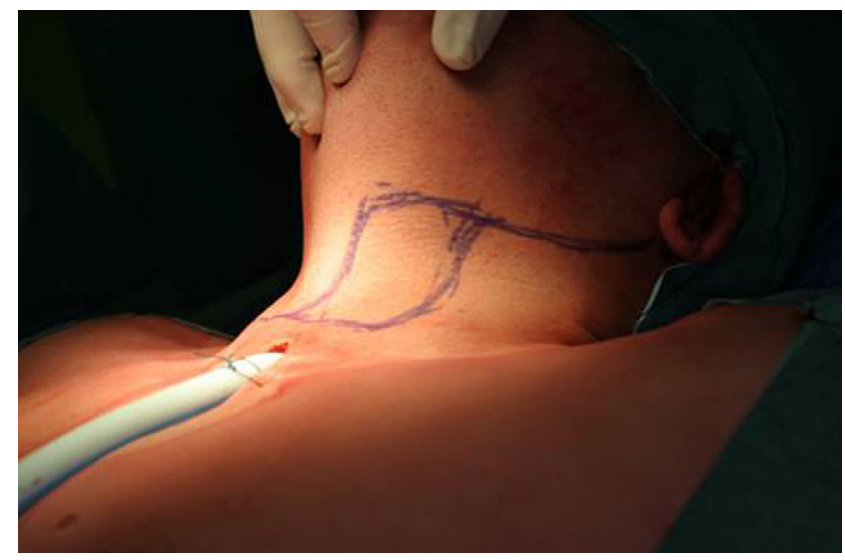

Figure 2. Pre operative skin design.

muscles are separated from the thyroid plane in order to identify the superior thyroid artery and vein pedicle (Fig. 3). ${ }^{8,9}$ Collateral veins and superior laryngeal artery (carefully separated from the superior laryngeal nerve) can be ligated, allowing securing the flap to the external carotid artery and the facial vein, or perhaps the internal jugular vein. The SH is usually upwardly sectioned at the insertion to the hyoid bone. The flap is then placed to repair

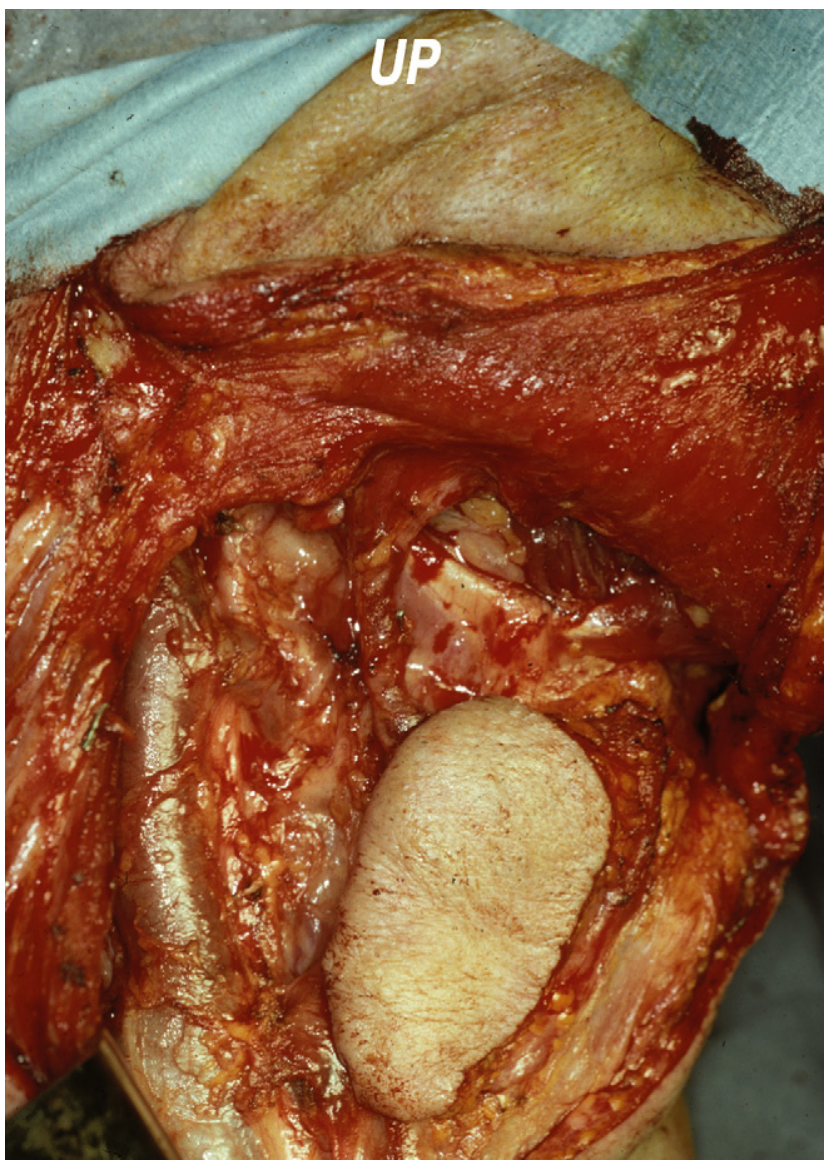

Figure 3. Infra hyoid musculo-cutaneous flap. Surgical aspect, front view. 


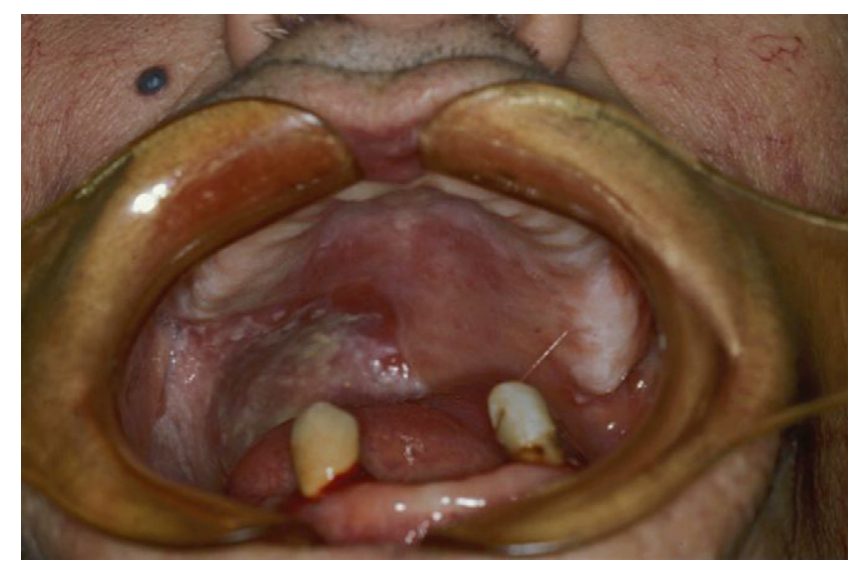

Figure 4. Post operative view. Right soft palate reconstruction with infra hyoid musculo-cutaneous flap.

the defect site (Fig. 4). Cutaneous closure of the donor site is performed without important difficulties (Fig. 5).

\section{Patients and treatments}

From 1996 to 2005, 23 consecutive patients, 19 men and 4 women, underwent IHMCF reconstruction after oropharynx cancer ablation - including a part of soft palate - and neck dissection, in one stage procedure. The extension limits of the tumour had not to go beyond the midline of the soft palate. The ages of the patients ranged from 39 to 71 years, with median age of 58 years. The series accounts 23 squamous cell carcinomas (100\%) arising from the mucosa of the oral cavity and oropharynx. The localization was velotonsil area for 20 patients and retro molar trigon for 3 patients. Twenty one patients (91\%) admitted to tobacco consumption and alcohol abuse. The disease was staged according to the $\mathrm{VI}^{\text {th }}$ edition of the TNM classification established by the UICC/AJCc. ${ }^{10}$ Four tumours were noted T1, 9 T2, 7 T3 and 3 T4. Nodes were staged as 5 N0, 5 N1, 3 N2a, 6 N2b, 3 N2c and 1 N3. Post operative radiotherapy was performed for 23 patients. All patients

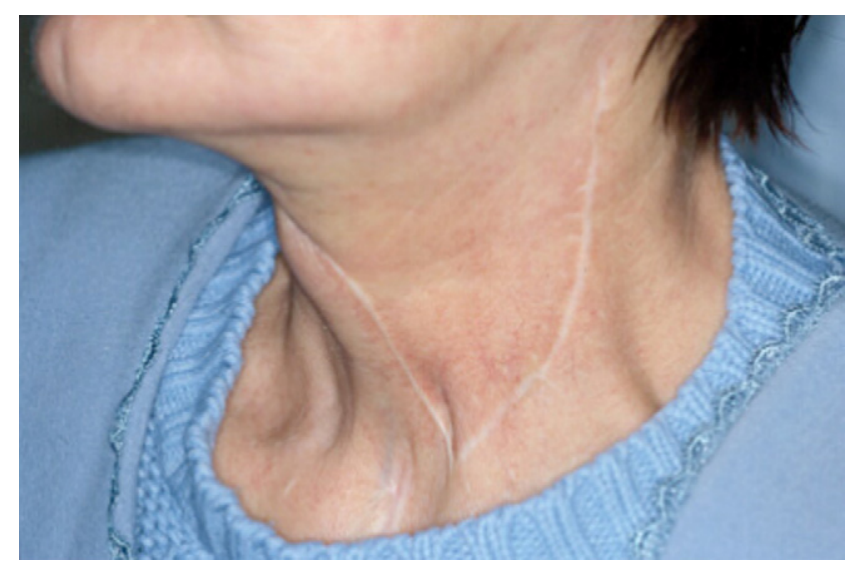

Figure 5. Post operative view. Donor site cicatrisation. underwent speech and swallowing evaluation and reeducation after surgery and radiotherapy.

In this series IHMCF reconstruction has been chosen instead of FRFF reconstruction or maxillofacial prosthesis.

\section{Results}

Nineteen patients had cicatrisation without complications for the flap or the donor site. Local complications occurred in 4 patients. In 2 cases we observed a partial skin paddle necrosis. In the other 2 cases the patients demonstrated a minor cervical dehiscence of the skin requiring only local care.

17/23 patients were able to eat normally (good deglutition) with good speech evaluation (good intelligibility). The remaining 6 patients had to adapt their eating habits by mincing (2/6) (fair deglutition) or by mixing (2/6) (bad deglutition) their food. The last 2 patients had fair speech evaluation (fair intelligibility) (Table 1). These six patients, for whom function was classified fair or bad, had T4 (2/6) or T3 (4/6) tumours. The two bad results were noted for patients who had presented in the past laryngeal or pharyngeal tumours. The $1^{\text {st }}$ was a second localization and the $2^{\text {nd }}$ was a third localization. For fair results, the delay of surveillance after surgery was too short for three patients (less than 12 months), one presented a second localization and the last obtained only fair results after reeducation. The extent of soft palate resection was varied: from the quarter to the half with no clear relation between the extent of the resection and the function quality (Table 2).

The delay of surveillance after surgery ranged from 6 months to 9 years, with median delay of 2 years and 9 months.

\section{Discussion}

Since 1979, Wang et al. ${ }^{11}$ performed a long series of IHMCF. Earliest studies were published from 1986 to 1994. ${ }^{4,11-13}$ Wang et al. ${ }^{11}$ reported 112 flaps which were successful in $90 \%$ of the cases (101 of 112 cases). The same success rate of IHMCF is noted by Zhao et al. ${ }^{14}$ who have concluded that cervical pedicle flaps have clinical value in selected patients needing reconstruction of small and medium - sized defects after intraoral cancer surgery. IHMCF is a versatile, reliable, and convenient flap suitable for repairing the defects in and around the oral cavity, particularly in the oropharynx, even in aged and weak patients. ${ }^{11}$ Since 1994 , we performed routinely IHMCF to reconstruct mucous defects in the head and neck region with this technique, which we subsequently modified for head and neck surgery and immediate reconstruction. ${ }^{15}$

At best, the flap extremity can reach a distance of $15 \mathrm{~cm}$ (theoretical) around its rotation axis. The effective region includes the cervical trachea up to the velotonsil, including the inferior facial cutaneous covering (under the labial tragus commissura). For soft palate, the maximum size of 
Table 1

Series description

\begin{tabular}{|c|c|c|c|c|c|}
\hline \multicolumn{2}{|c|}{ Classification } & \multirow{2}{*}{$\frac{\text { Localization }}{20 \text { velotonsil }}$} & \multirow{2}{*}{$\frac{\text { Post operative treatment }}{23 \text { radiotherapy }}$} & \multirow{2}{*}{$\begin{array}{l}\text { Local complications } \\
2 \text { partial skin } \\
\text { paddle necrosis }\end{array}$} & \multirow{2}{*}{$\frac{\text { Function evaluation }}{17 \text { good }}$} \\
\hline $4 \mathrm{~T} 1$ & $5 \mathrm{N0}$ & & & & \\
\hline $9 \mathrm{~T} 2$ & $5 \mathrm{~N} 1$ & $\begin{array}{l}3 \text { retro molar } \\
\text { trigon }\end{array}$ & $\begin{array}{l}23 \text { speech and } \\
\text { swallowing reeducation }\end{array}$ & $\begin{array}{l}2 \text { minor cervical } \\
\text { dehiscence }\end{array}$ & 4 fair \\
\hline $7 \mathrm{~T} 3$ & $3 \mathrm{~N} 2 \mathrm{a}$ & & & & $2 \mathrm{bad}$ \\
\hline $3 \mathrm{~T} 4$ & $\begin{array}{l}6 \mathrm{~N} 2 \mathrm{~b} \\
3 \mathrm{~N} 2 \mathrm{c} \\
1 \mathrm{~N} 3\end{array}$ & & & & \\
\hline
\end{tabular}

defect that could be safely reconstructed with the IHMCF is the half. Functionally, flap resection does not induce phonatory, respiratory or swallowing complications. The size of the cutaneous flap sampled was always compatible with a direct suture of the donor site without cicatrisation complication.

In our experience, the results were comparable with those published in the literature. ${ }^{4,11-13}$ The lack of ability to reconstruct the dynamic function of the soft palate continues to be disappointing. Limited studies have shown promise in soft palate reconstruction without the complications of velopharyngeal insufficiency. The lack of a uniform classification for palate defects has limited prospective comparison of reconstructive methods. ${ }^{16}$ The usual respect of contraindications helped avoiding the complications encountered by other authors. ${ }^{11}$ Contra indications of IHMCF such as previous thyroid surgery or radical neck dissection must be respected; relative contra indication is represented by previous cervical radiotherapy. It is acceptable to use material from a metastatic neck for defect cover in the cases where the vascular pedicle of the flap and the IHMCF itself are not in the tumour and are at least at $30 \mathrm{~mm}$ of cancerous tissue.

In case of soft palate reconstruction, it is useful to preserve the motor innervation of the infrahyoid muscles provided by the descending branch of the hypoglossal nerve (the ansa cervicalis), that is kept with the flap during its new positioning. The main advantage of this voluntary innervated flap is the prevention of atrophies and the improvement of scarring qualities of the reconstructed soft palate. ${ }^{17}$ The function qualities are also improved by this innervation conservation which allows synchronous contraction of the two sides of soft palate during swallowing. As Wang et al. published, ${ }^{11}$ a minor motricity reappears within 12 months after intervention.

The IHMCF is a versatile, reliable and convenient flap, with interesting plastic qualities, suitable for repairing small and medium sized defects; ${ }^{15}$ this is an additional tool in the therapeutic possibilities for cervicofacial reconstruction. It can be used in combination with other flaps, and in selected cases, as soft palate reconstruction, obviates the need for a microvascular FRFF or maxillofacial prosthesis. This flap is thin, pliable, so that is particularly useful in oral cavity reconstructions and, in our experience, the functional results are comparable to those of the FRFF reconstruction for small and medium sized defects. The IHMCF has the particularity to remain the anatomy after reconstruction, which is less possible with FRFF or maxillofacial prosthesis.

The realisation of a maxillofacial prosthesis is another solution for these patients. Prosthetic treatment of soft palate defects varies based on the extent and site of the defect. The goal of treatment is to attain velopharyngeal closure during function, which allows normal speaking and swallowing and keeps the patient relatively comfortable. While maxillofacial prosthetic treatment is not a substitute for plastic and reconstructive surgery, in certain circumstances it may be an alternative. Certain patients may simply not be

Table 2

Fair or bad function description

\begin{tabular}{|c|c|c|c|c|c|}
\hline & $\begin{array}{l}\text { Classification } \\
\text { TNM }\end{array}$ & $\begin{array}{l}\text { Extent of soft } \\
\text { palate resection }\end{array}$ & $\begin{array}{l}\text { Function } \\
\text { impairement }\end{array}$ & $\begin{array}{l}\text { Main reason of function } \\
\text { impairement }\end{array}$ & $\begin{array}{l}\text { Delay of surveillance } \\
\text { after surgery }\end{array}$ \\
\hline Fair result \#1 & T3 N1 M0 & Quarter of soft palate & Fair intelligibility & $\begin{array}{l}\text { Delay too short for } \\
\text { complete reeducation }\end{array}$ & 8 months \\
\hline Fair result \#2 & T3 N1 M0 & Quarter of soft palate & Fair deglutition & Fair reeducation results & 16 months \\
\hline Fair result \#3 & T3 N2a M0 & Third of soft palate & Fair deglutition & $\begin{array}{l}\text { Delay too short for } \\
\text { complete reeducation }\end{array}$ & 6 months \\
\hline Fair result \#4 & T3 N2c M0 & Quarter of soft palate & Fair intelligibility & $\begin{array}{l}\text { Second localization and } \\
\text { delay too short for } \\
\text { complete reeducation }\end{array}$ & 10 months \\
\hline Bad result \#1 & T4 N1 M0 & Half of soft palate & Bad deglutition & Third localization & 23 months \\
\hline Bad result \#2 & T4 N2a M0 & Third of soft palate & Bad deglutition & Second localization & 47 months \\
\hline
\end{tabular}


good candidates for plastic surgery because of their advanced age, poor health, very large deformity, or poor blood supply to irradiated tissue. Moreover, maxillofacial prosthetic treatment is indicated when anatomical parts of the head and neck are not replaceable by living tissue or when recurrence of malignancy is likely.

Nevertheless, in patients with soft palate defects, it is difficult to obtain sufficient retention, support, and stability of the obturator prosthesis. In addition, its mobility during various functions is considered to be large.

Although the system of speech evaluation was subjective in our series, but standardized by the same speech therapist, the results obtained seemed equivalent to those obtained by Wang et al. ${ }^{11}$ and Zuydam et al. ${ }^{18}$ Four fair results and two bad results were observed. On the one hand, these results seemed to be related to the tumour stage (T3 or T4) and not to the extent of soft palate resection (for some cases, good results have been obtained after resection of the half of soft palate) and on the other hand, three out of four fair results had a delay of surveillance after surgery less than 12 months, which can also explain these functional results. The two bad results were noted for T4 tumours.

The indications of this flap remain numerous for the upper aerodigestive tract allowing the repair of large mucous or cutaneous defects with acceptable functional or aesthetic sequelae.

Our surgical technical research has led us to the laryngeal and pharyngolaryngeal reconstruction (i.e. after near total resection) with the IHMCF and in some specific case, partial reconstruction of cervical esophagus. Our primary results seem to confirm the elective choice of this flap for these indications.

\section{References}

1. McCombe D, Lyons B, Winkler R, Morrison W. Speech and swallowing following radial forearm flap reconstruction of major soft palate defects. Br J Plast Surg 2005;58:306-11.

2. De Bree R, Hartley C, Smeele LE, Kuik DJ, Quak JJ, Leemans CR. Evaluation of donor site function and morbidity of the fasciocutaneous radial forearm flap. Laryngoscope 2004;114:1973-6.
3. Brown JS, Zuydam AC, Jones DC, Rogers SN, Vaughan ED. Functional outcome in soft palate reconstruction using a radial forearm free flap in conjunction with a superiorly based pharyngeal flap. Head Neck 1997;19:524-34.

4. Rojananin S, Suphaphongs N, Ballantyne AJ. The infrahyoid musculocutaneous flap in head and neck reconstruction. Am J Surg 1991; 162:400-3.

5. Calloc'h F, Prades JM, Chelikh L, Dalmonego V, Martin Ch. Infrahyoid paramedian musculocutaneous flap. Anatomical bases. Review of the literature. J Fr Otorhinolaryngol 1996;45:203-9.

6. Deganello A, De Bree R, Dolivet G, Leemans CR. Infrahyoid myocutaneous flap reconstruction after wide local excision of a Merkel cell carcinoma. Acta Otorhinolaryngol Ital 2005;25:50-4.

7. Faucher A, Verhulst J, Majoufre C, de Bonfils C. Infrahyoid musculocutaneous flaps: anatomical bases and indications in cervicofacial oncologic surgery. Rev Laryngol Otol Rhinol (Bord) 1997;118:43-6.

8. Eliachar I, Marcovich A, Har Shai Y, Lindenbaum E. Arterial blood supply to the infrahyoid muscles: an anatomical study. Head Neck Surg 1984;7:8-14.

9. Lockhart R, Menard P, Chout P, Favre-Dauvergne E, Berard P, Bertrand JC. Infrahyoid myocutaneous flap in reconstructive maxillofacial cancer and trauma surgery. Int J Oral Maxillofac Surg 1998;27: $40-4$.

10. UICC Union Internationale Contre le Cancer. In: Hermanek P, Sobin LH, editors. TNM classification of malignant tumours. $4^{\text {th }}$ ed. Paris: Springer-Verlag; 1988, p. 13-32.

11. Wang HS, Shen JW, Ma DB, Wang J, Tian A. The infrahyoid myocutaneous flap for reconstruction after resection of head and neck cancer. Cancer 1986;57:663-8.

12. Dolivet G, Faucher A, Majoufre C, Micheik J, Renaud-Salis JL. The infra-hyoid musculo-cutaneous flap in head and neck reconstructive surgery: technique and first results. Rev Laryngol 1994; 115:225-9.

13. Magrin J, Kowalski LP, Santo GE, Walksmann G, DiPaula RA. Infrahyoid myocutaneous flap in head and neck reconstruction. Head Neck 1993;15:522-5.

14. Zhao YF, Zhang WF, Zhao JH. Reconstruction of intraoral defects after cancer surgery using cervical pedicle flaps. J Oral Maxillofac Surg 2001;59:1142-6.

15. Dolivet G, Gangloff P, Sarini J, et al. Modification of the infra hyoid musculo-cutaneous flap. Eur J Surg Oncol 2005;31:294-8.

16. Van der Sloot PG. Hard and soft palate reconstruction. Curr Opin Otolaryngol Head Neck Surg 2003;11:225-9.

17. Remmert SM, Sommer KD, Majocco AM, Weerda HG. The Neurovascular Infrahyoid Flap: a new method for tongue reconstruction. Plast Reconstr Surg 1997;99:613-8.

18. Zuydam AC, Lowe D, Brown JS, Vaughan ED, Rogers SN. Predictors of speech and swallowing function following primary surgery for oral and oropharyngeal cancer. Clin Otolaryngol 2005;30:428-37. 